$$
\begin{aligned}
& \text { تأثير تغير وقت المكوث الهيدروليكي والنسبة الحجمية للمنطقة اللاهوائية إلى الهوائية في } \\
& \text { كفاءة أداء وحدات الحمأة المنشطة المطورة بنظة المهام (باردنفو) }
\end{aligned}
$$

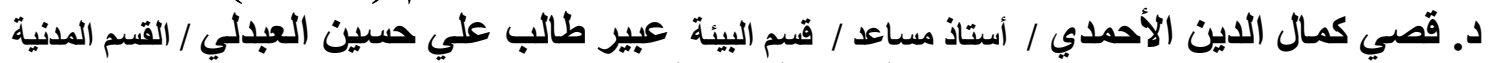

$$
\begin{aligned}
& \text { كلية الهندسة / جامعة الموصل } \\
& \text { الخلاصة }
\end{aligned}
$$

Keywords: Biological treatment, Bardenpho, HDT, Volumetric ratio, Anaerobic

\title{
Effect of the hydraulic detention time and the volumetric ratio of anaerobic to aerobic zone on the efficiency of the upgraded activated sludge units using (Bardenpho) system
}

\author{
Dr. K. K. Al-Ahmady / Ass. Prof \\ Abeer.T. A. H. AL-Abdaly \\ College of Engineering / University of Mosul,
}

Abstract

In this research, five experimental plants have been established and operated using synthetic domestic wastewater in order to study the effect of some operational parameters on the removal efficiency of organic and nutrients pollutants in Bardenpho Process. The results of the research proved that the removal efficiency of organic, nitrogen, and phosphorus materials were higher in the reactors that work by Bardenpho process comparing to the ordinary activated sludge system. Also the biological sludge resulted from Bardenpho reactors has better settling characteristics. Likewise, the pH values in the plants work by Bardenpho process were lower than those in the plant that work by ordinary activated sludge system. The results of the study also shown that the removal efficiency of organic materials in the Bardenpho reactors increases by the reduction of volumetric ratio of the anaerobic to aerobic zone, in contrast, the concentrations of Nitrate, Ammonia, and Phosphate decrease by the reduction this ratio, in addition, the value of SVI decreases by increasing the size of anaerobic zone. On the other hand, The results also proved that increasing the hydraulic detention time (HRT) lead to increase the efficiency of removing organic, nitrogen, and phosphorus materials of the biological reactors that work by Bardenpho process. Moreover, increasing the HRT leads to increase value of the sludge volume index (SVI) at all of the Bardenpho and ordinary activated sludge reactors. In contrast, the value of $\mathrm{pH}$ drops by the increasing of hydraulic detention time. 
مع زيادة أهمية معالجة المركبات النتروجينية و الفسفور (2003, Metcalf \&Eddy) ووجود العديد من محطات

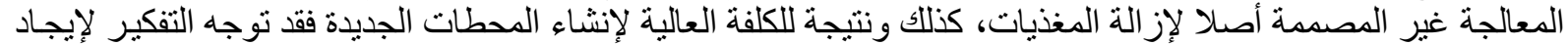

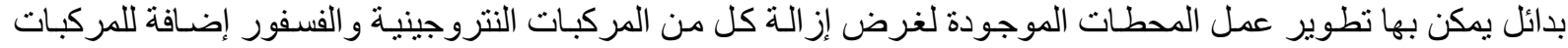

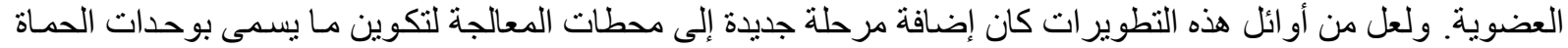

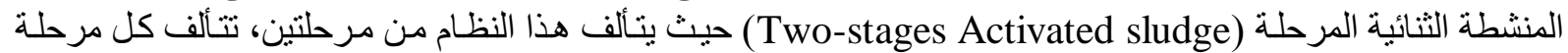

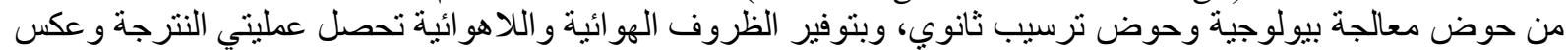

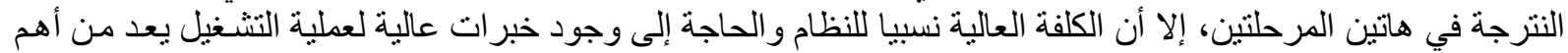

المعوقات ألتي واجهت تطبيق هذا الترتيب (2003, Metcalf \&Eddy).

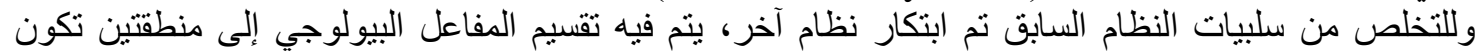

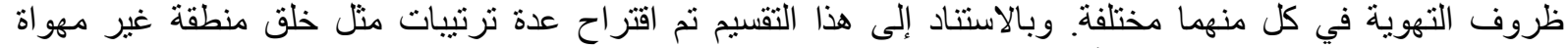
(anoxic zone(AX))

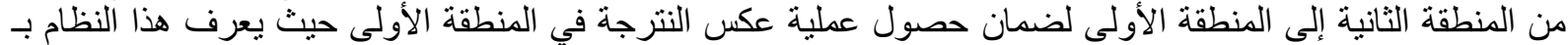
(Pre anoxic)

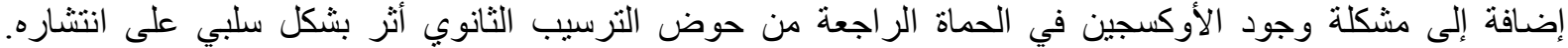

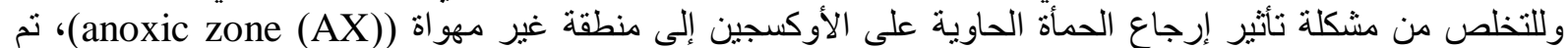

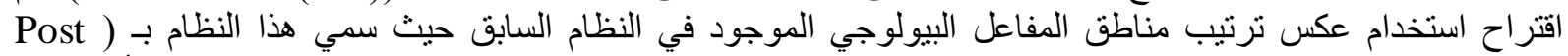

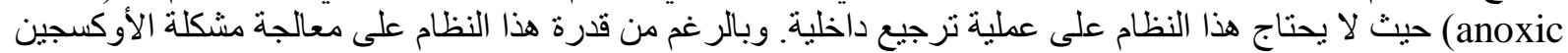

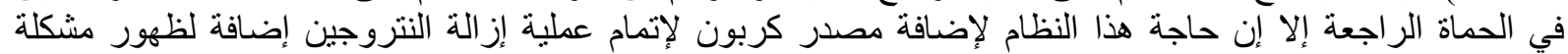
ارتفاع الحمأة (Rising sludge) في حوض الترسيب الثانوي نتيجة لتحرر غاز النتروجين قد حد من استخدامه

.(Jeyanayagam ,2005 ) (Metcalf \&Eddy,2003)

وبسبب المشاكل التي رافقت النظامين السابقين تم اقتراح استخدام نرتيب نظام معالجة مختلف سمي بنظام

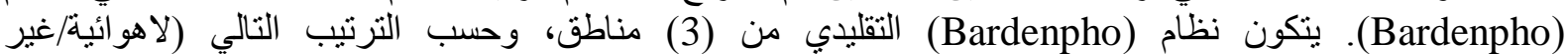

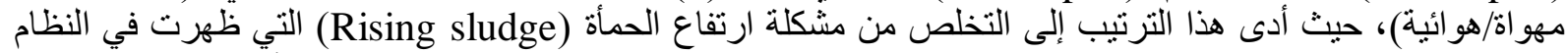

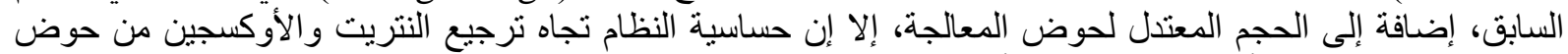
الترسيب إلى المنطقة الأولى إللاهو ائية قد أدى إلى الحد من استخدامه (2003, (Metcalf \&Eddy).

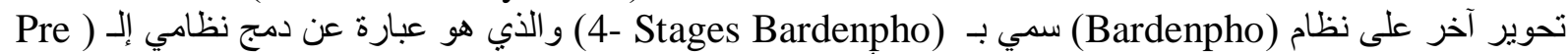

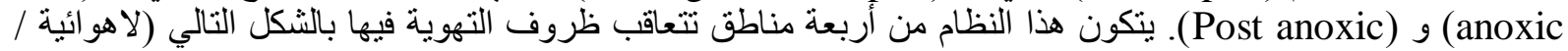
هو ائية /غير مهواة /هو ائية)، بالإضافة إلى إن الحمأة الناتجة من المنطقة الأخيرة لا تحتاج إلى أب معالجات إضافية ويمكن

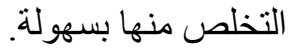
يهدف هذا البحث إلى إيجاد تأثثير تغيير زمن المكوث الهيدروليكي و النسبة الحجمية للمنطقة اللاهو ائية إلى المنطقة

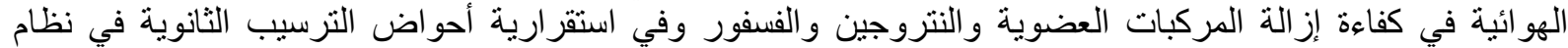

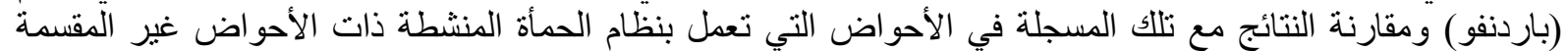

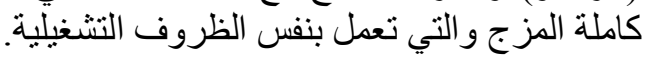

الار اسات السابقة

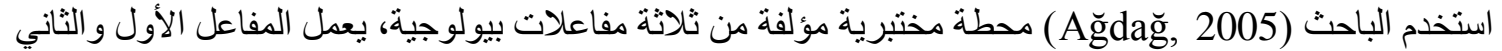

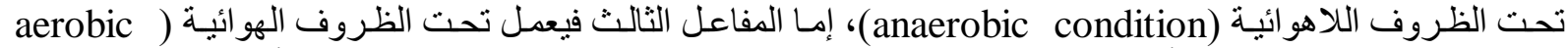
(condition

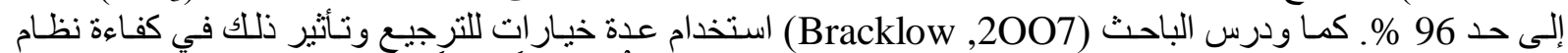

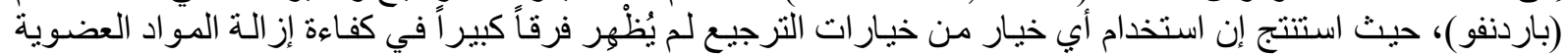

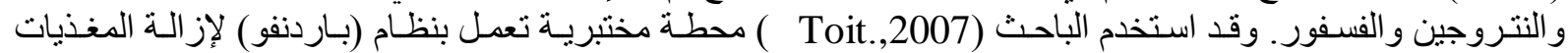

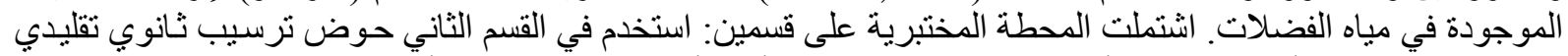

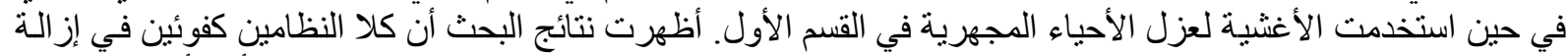
المو اد الصلبة العالقة والمواد العضوية والنتروجينية والفسفور في حين كانت كفاءة الإز اللة في النظام الأول أكثر منها في في الني 
النظام الثناني، وقد لوحظ إن كمية الحمأة الناتجـة في النظام الأول تكون كبيرة مقارنـة مع النظام الثناني. واستخدم الباحث

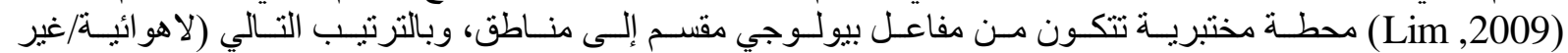

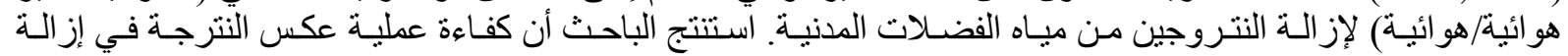

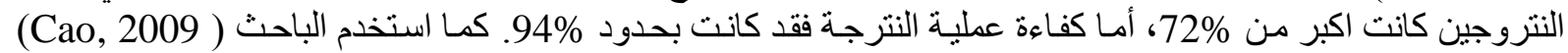

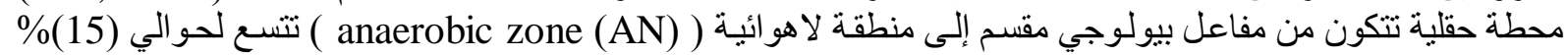

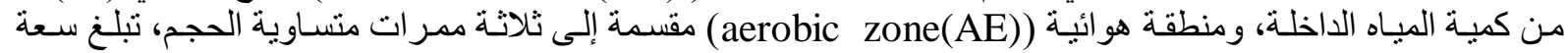

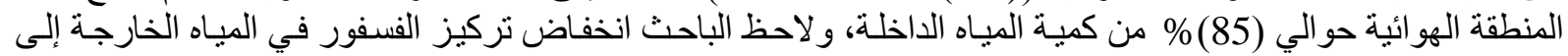

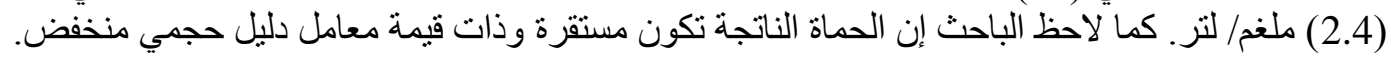

\section{المواد وطرائق العمل \\ a}

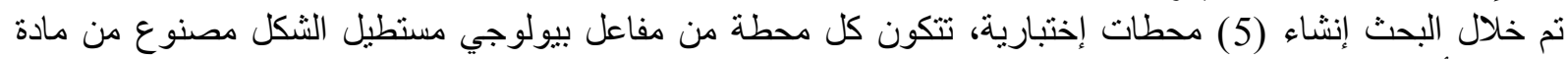

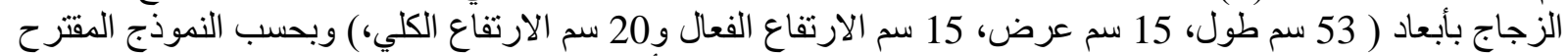

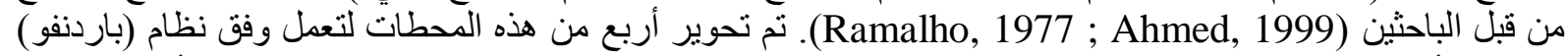

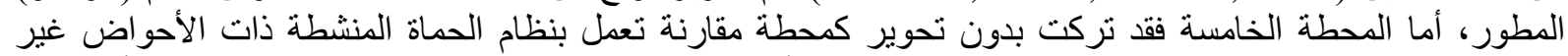

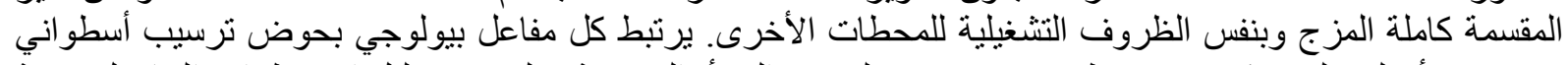

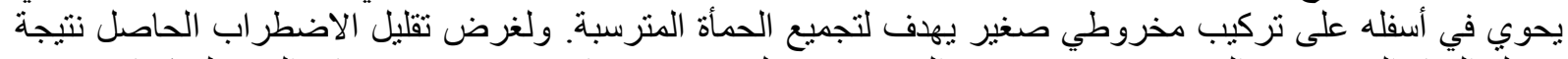

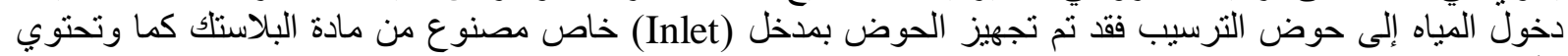

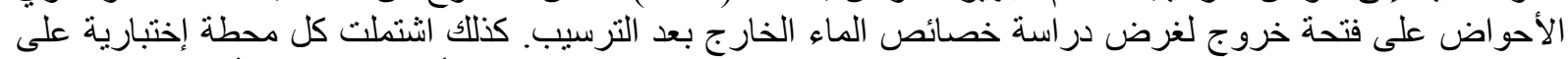

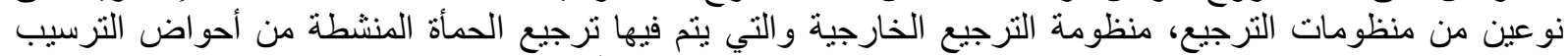

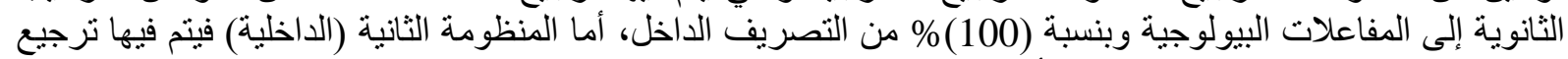

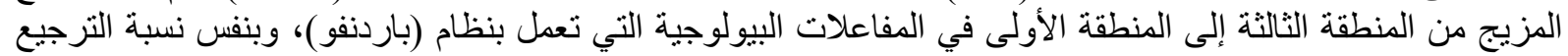

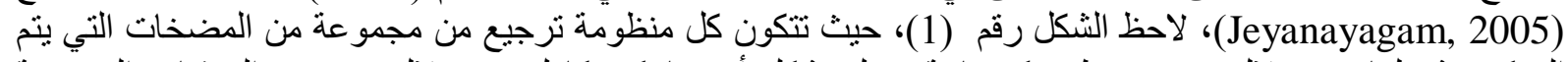

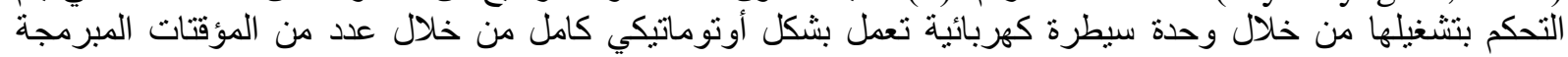

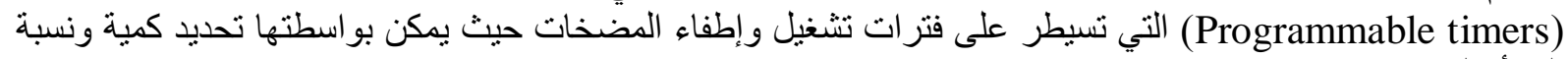

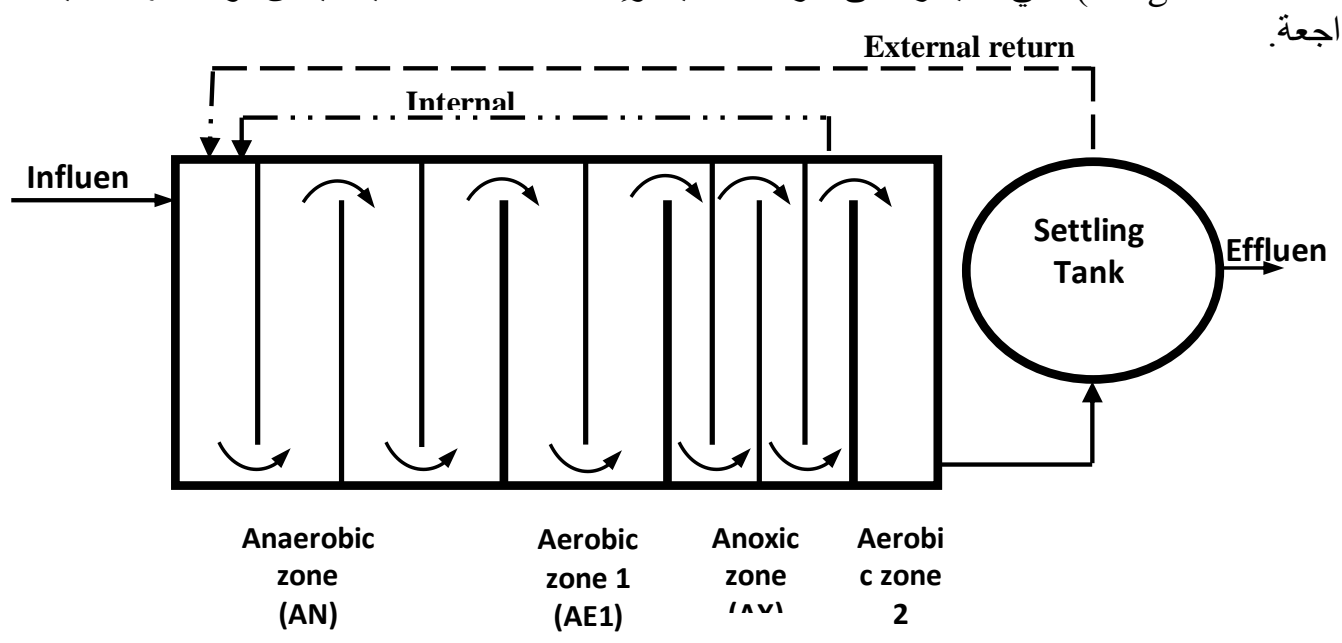

الحمأة الر اجعة.

شكل رقم (1) : مخطط يوضح المحطة الاختبارية التي تعمل بنظام (باردنفو).

و لغرض نوفير التهوية والمزج اللازمين في المناطق الهوائية للمفاعلات البيولوجية التي تعمل بنظام (باردنفو)

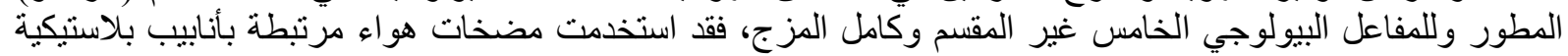

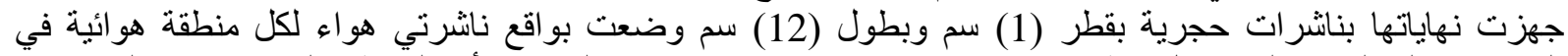

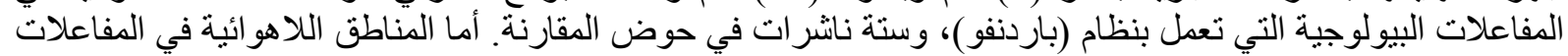

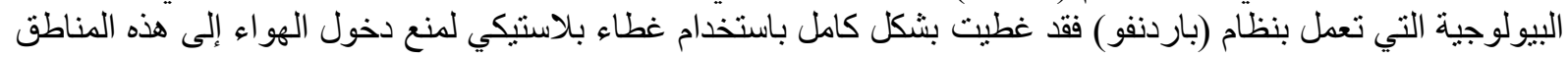


كذلك ولغرض توفير المزج اللازم لهذه المناطق فقد ثقبت الأغطية البلاستيكية لإنز ال عمود معدني يرتبط من الأسفل

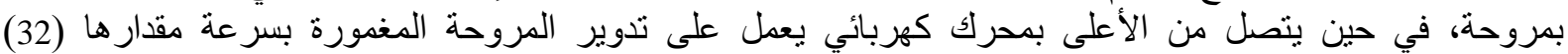
دورة/دقيقة وبما يضمن حصول عملية المزج الكامل لاحظظ الثكل رقم (2).

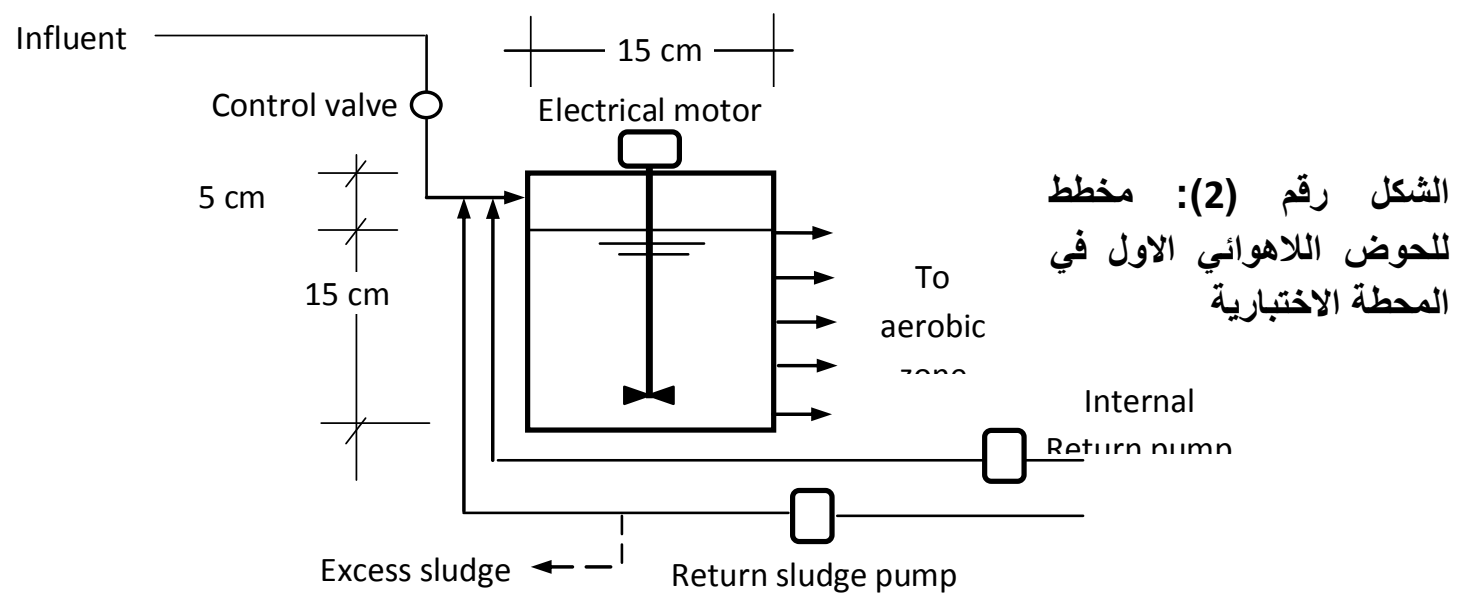

اعتمد أسلوب التشغيل المستمر(Continuous mode of operation) للمحطة الاختبارية، حيث تمت تغذية بلإنية

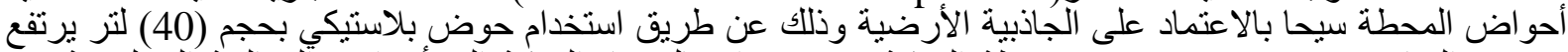

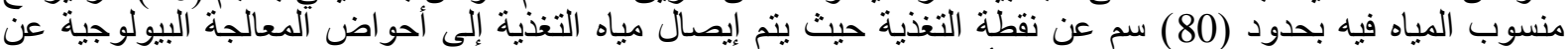

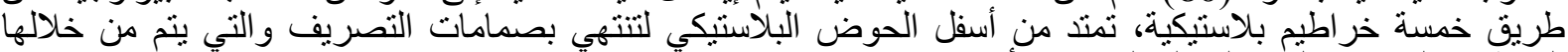

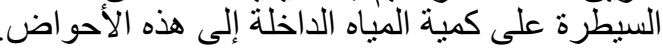

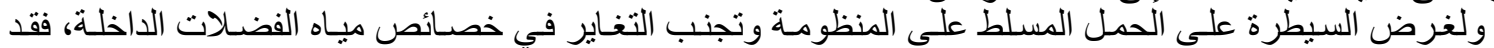

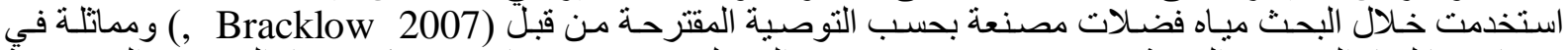
خصائصها لمياه الفضلات المدنية (Nopens, 2001). يبين الجدول رقم (1) خصائص وتركيب مياه الفضلات المستخدمة في البحث.

جدول رقم (1): المواد الداخلة في تصنيع مياه الفضلات

\begin{tabular}{|c|c|c|c|c|c|}
\hline الفسفور الكلي & (التتروجينين الكلي & $\begin{array}{c}\text { COD } \\
\text { (ملغف/لتر) }\end{array}$ & (غرام/كتر) & (ملفم/التر) & المواد المستخدمة \\
\hline 0 & 27 & 0 & 0.104 & 104 & $\mathrm{NH}_{4} \mathrm{CL}$ \\
\hline 0 & 1 & 25.9 & 0.0259 & 25.9 & Pepton \\
\hline 4.3 & 0 & 0 & 0.01935 & 19.35 & $\mathrm{KH}_{2} \mathrm{PO}_{4}$ \\
\hline 0 & 0 & 271 & 0.271 & 271 & النشأ \\
\hline 1.96 & 11.96 & 200 & 0.200 & 200 & MILK \\
\hline 1.74 & 0 & 0 & 0.01 & 10.034 & $\mathrm{~K}_{2} \mathrm{HPO}_{4}$ \\
\hline 0 & 0 & 0 & 0.0058 & 5.8 & $\mathrm{MgSO}_{4} \cdot 7 \mathrm{H}_{2} \mathrm{O}$ \\
\hline 0 & 21.4 & 11.61 & 0.0458 & 45.87 & Urea \\
\hline 8 & 40 & 500 & & & المجموع \\
\hline
\end{tabular}

b المراحل والظروف التشغيلية

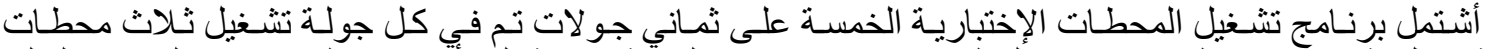

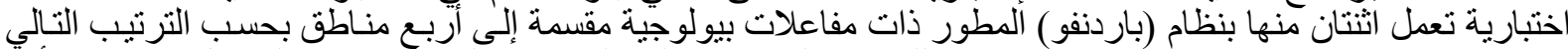
(AN/AE1/AX/AE2)

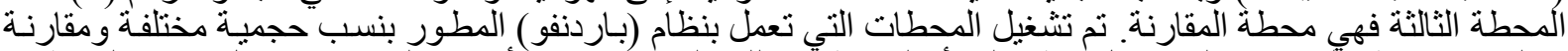

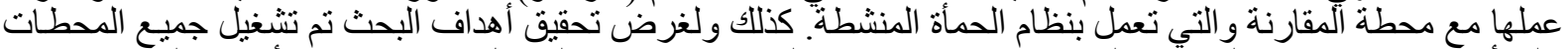

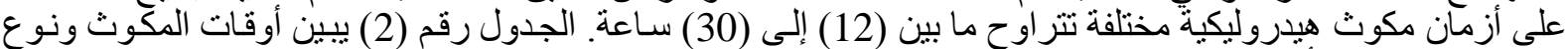

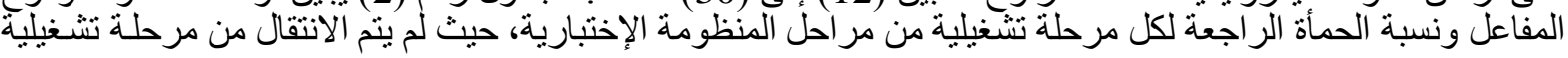


ألأحمدي: تأثير تغير وقت المكوث الهيدروليكي والنسبة الحجمية للمنطقة اللاهوائية إلى الهوائية في كفاعة أداء

إلبي أخرى إلا بعد استقرار المعالجة البيولوجية، وقد تم الاستدلال على حالة من خلال ثبوت كل من كفاءة المعالجة وتركيز

الأحياء المجهرية فيها (Ramalho,1977).

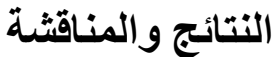

1. تأثير وقت المكوث الهنئنة الهيدروليكي

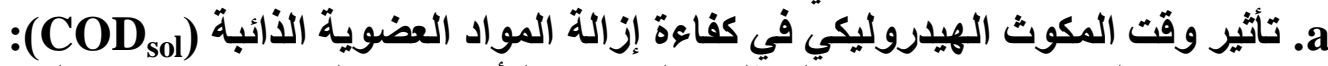

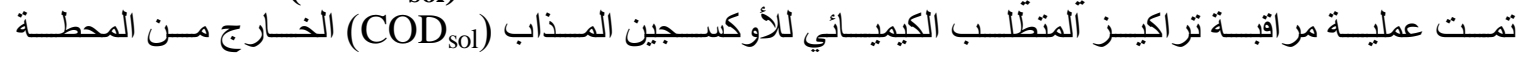

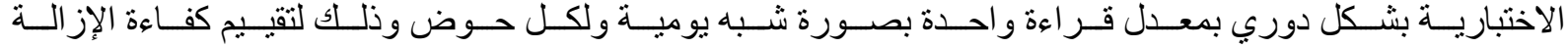

جدول رقم (2): المراحل التشغيلية للمحطات الاختبارية

\begin{tabular}{|c|c|c|c|c|c|}
\hline $\begin{array}{c}\text { الحجبية } \\
\text { AE1:AE2 }\end{array}$ & $\begin{array}{c}\text { النسبة: } \\
\text { (AN : AX) } \\
\text { (ANمية }\end{array}$ & $\begin{array}{c}\text { النسبة الحجمية } \\
\text { (AN+AX) } \\
\text { : } \\
\text { AE1+AE2 }\end{array}$ & (المكوثة & المفاعل & لمفأعل \\
\hline \multicolumn{6}{|c|}{ الجولة الأولى } \\
\hline $2: 1$ & $2: 1$ & $5: 1$ & 12 & مقسم & 12.15 \\
\hline \multirow[t]{2}{*}{$2: 1$} & $2: 1$ & $4: 1$ & 12 & مقسم & 12.15 \\
\hline & & & 12 & غير مقسم & 12.15 \\
\hline \multicolumn{6}{|c|}{ الجولة الثانية } \\
\hline $2: 1$ & $2: 1$ & $3: 1$ & 12 & مقسم & 12.15 \\
\hline \multirow{2}{*}{$2: 1$} & $2: 1$ & $2: 1$ & 12 & مقسم & 12.15 \\
\hline & & & 12 & غير مقسم & 12.15 \\
\hline \multicolumn{6}{|c|}{ الجولة الثالثة } \\
\hline $2: 1$ & $2: 1$ & $5: 1$ & 18 & مقسم & 12.15 \\
\hline \multirow[t]{2}{*}{$2: 1$} & $2: 1$ & $4: 1$ & 18 & مقسم & 12.15 \\
\hline & & & 18 & غير مقسم & 12.15 \\
\hline \multicolumn{6}{|c|}{ الجولة الرابعة } \\
\hline $2: 1$ & $2: 1$ & $3: 1$ & 18 & مقسم & 12.15 \\
\hline \multirow[t]{2}{*}{$2: 1$} & $2: 1$ & $2: 1$ & 18 & مقسم & 12.15 \\
\hline & & & 18 & غير مقسم & 12.15 \\
\hline \multicolumn{6}{|c|}{ الجولة الخامسة } \\
\hline $2: 1$ & $2: 1$ & $5: 1$ & 24 & مقسم & 12.15 \\
\hline \multirow[t]{2}{*}{$2: 1$} & $2: 1$ & $4: 1$ & 24 & مقسم & 12.15 \\
\hline & & & 24 & غير مقسم & 12.15 \\
\hline \multicolumn{6}{|c|}{ الجولة السادسة } \\
\hline $2: 1$ & $2: 1$ & $3: 1$ & 24 & مقسم & 12.15 \\
\hline \multirow[t]{2}{*}{$2: 1$} & $2: 1$ & $2: 1$ & 24 & مقسم & 12.15 \\
\hline & & & 24 & غير مقسم & 12.15 \\
\hline \multicolumn{6}{|c|}{ الجولة السابعة } \\
\hline $2: 1$ & $2: 1$ & $5: 1$ & 30 & مقسم & 12.15 \\
\hline \multirow[t]{2}{*}{$2: 1$} & $2: 1$ & $4: 1$ & 30 & مقسم & 12.15 \\
\hline & & & 30 & غير مقسم & 12.15 \\
\hline \multicolumn{6}{|c|}{ الجولة الثامنة } \\
\hline $2: 1$ & $2: 1$ & $3: 1$ & 30 & مقسم & 12.15 \\
\hline \multirow[t]{2}{*}{$2: 1$} & $2: 1$ & $2: 1$ & 30 & مقسم & 12.15 \\
\hline & & & 30 & غير مقسم & 12.15 \\
\hline
\end{tabular}




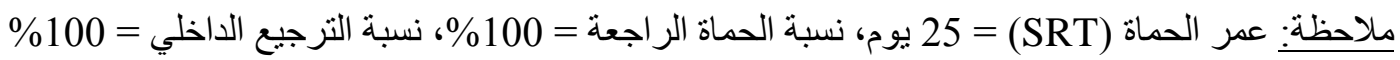

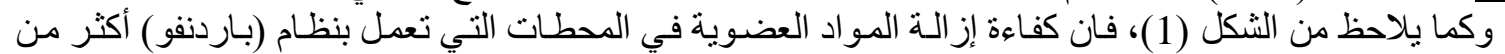

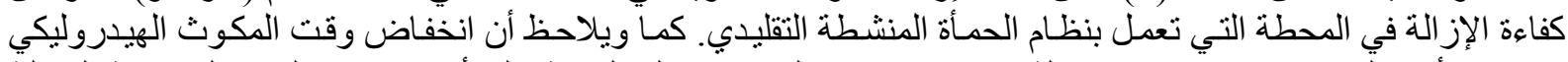

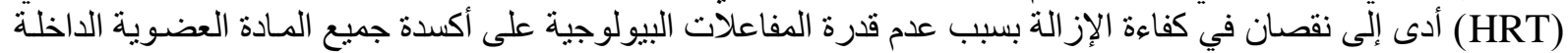

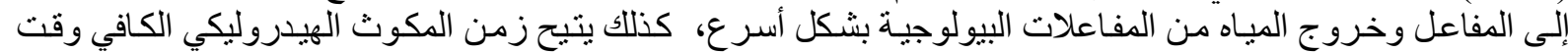

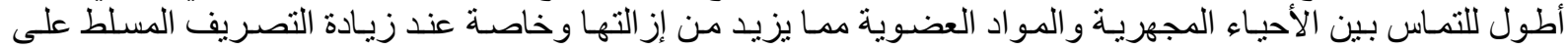

المنظومة وهذا يتو افق مع ما جاء به كل من: (Obaja 2002) (Metcalf and Eddy 2003).

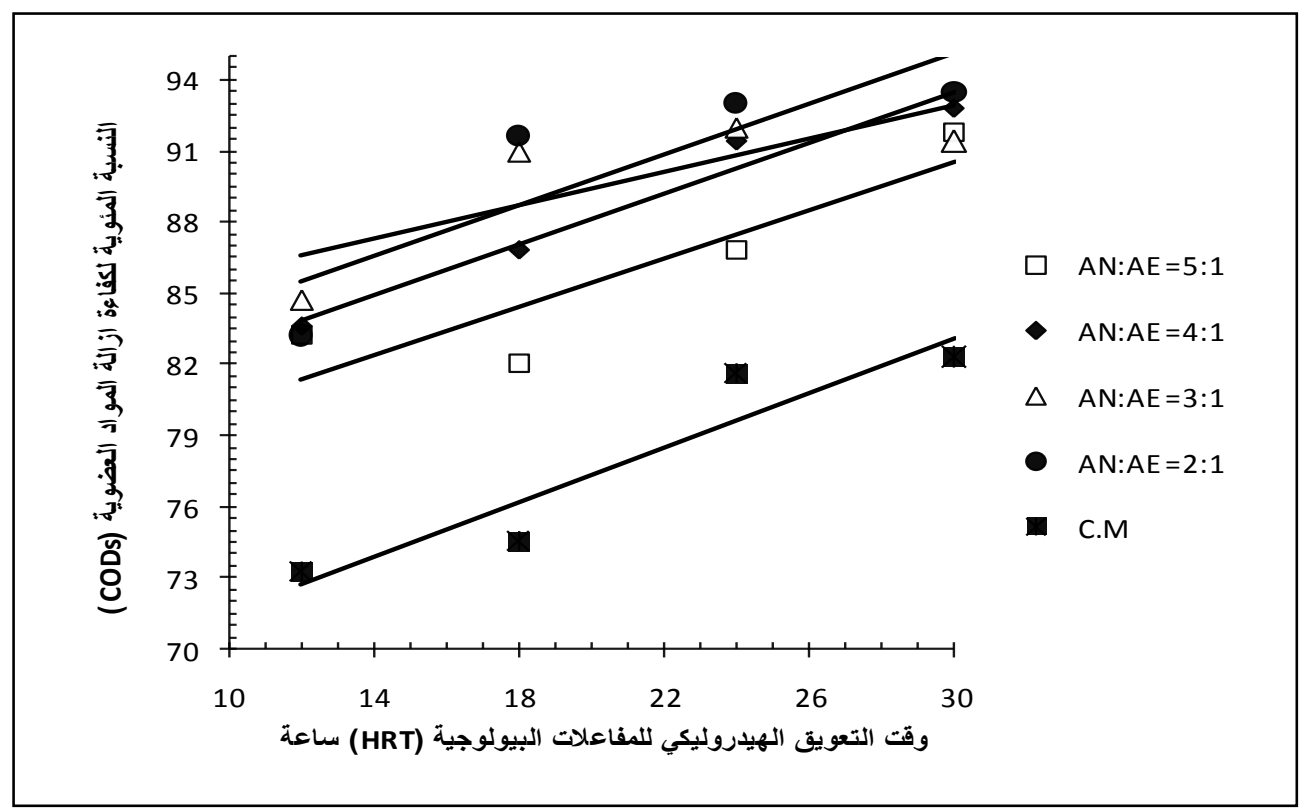

الثكل(1): العلاقة بين وقت التعويق الهيدروليكي (HRT) بكفاعة إزالة المواد العضوية (COD الإختبارية وللمراحل التثغيلية الأربع.

b. تأثير وقت المكوث الهيدروليكي في كفاءة إزالة النترات (NO3):

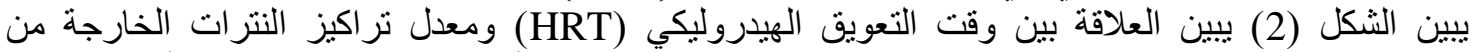

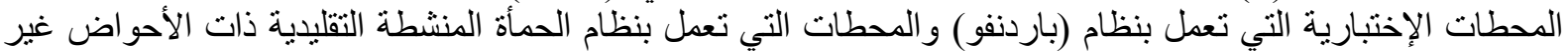

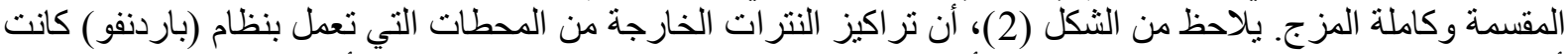

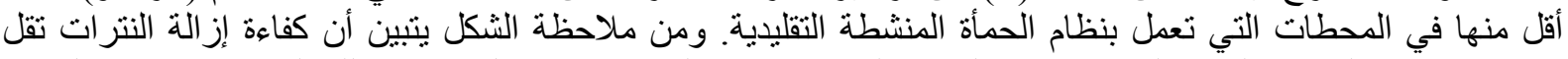

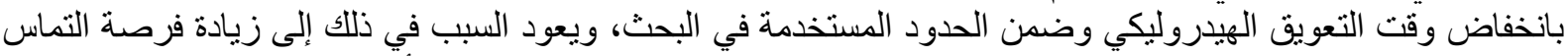

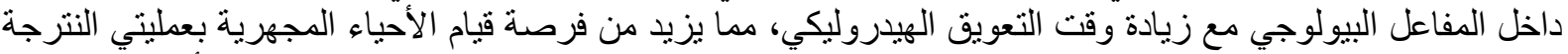

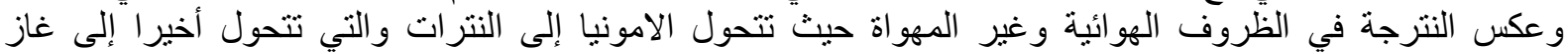

النتروجين (Obaja, 2002).

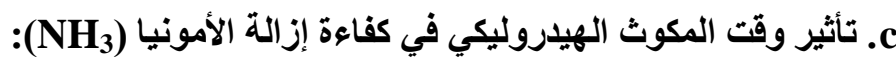

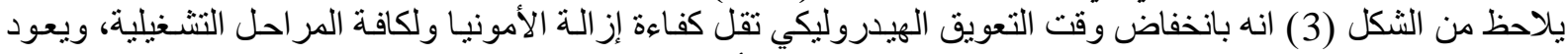

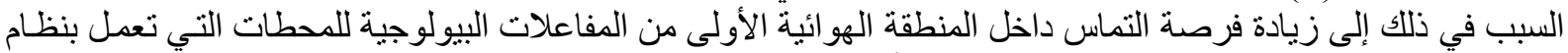

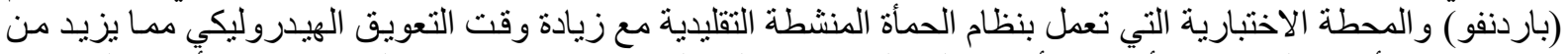

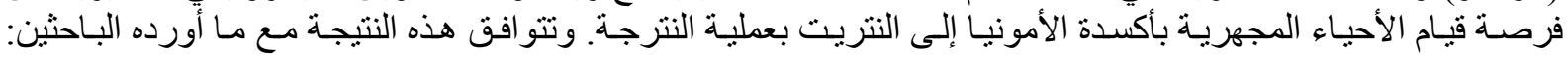

.(Obaja, 2002) 
ألأحمدي: تأثير تغير وقت المكوث الهيدروليكي والنسبة الحجمية للمنطقة اللاهوائية إلى الهوائية في كفاءة أداء

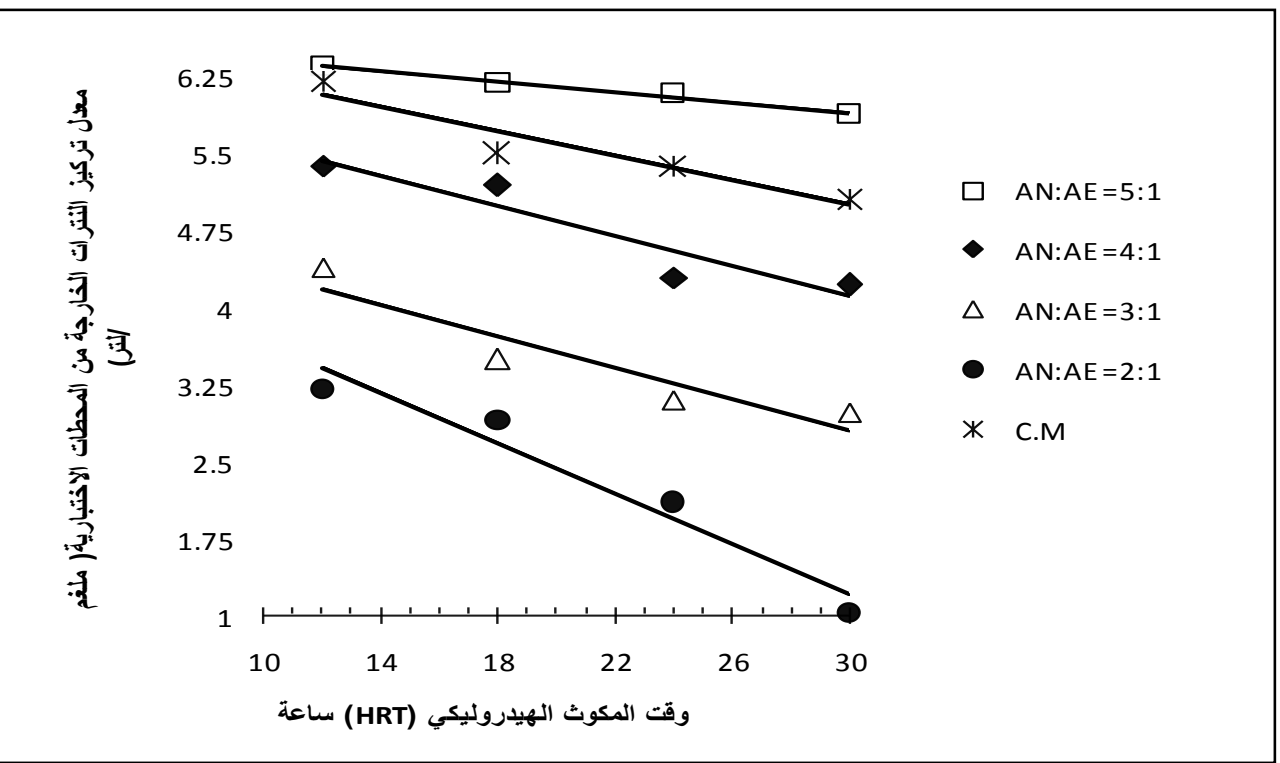

الثكل (2): العلاقة بين وقت التعويق الهيدروليكي (HRT) للمفاعل البيولوجي ومعدل تركيز النترات المتبقي الخارج

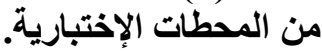

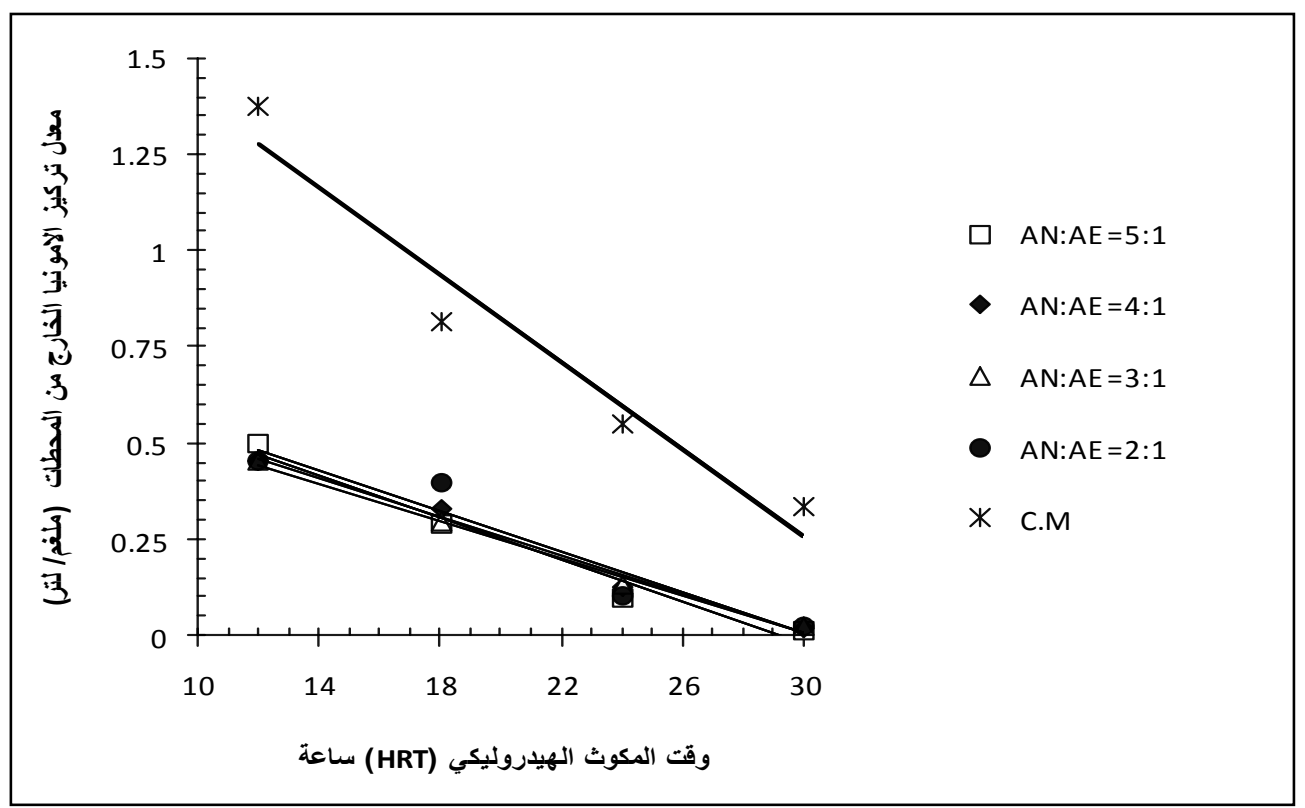

الثكل (3): العلاقة بين وقت التعويق الهيروليكي (HRT) للمفاعل البيولوجي ومعدل تركيز الأمونيا المتبقي الخارج من المحطات الاختبارية.

d تأثير وقت المكوث الهيدروليكي في كفاءة إزالة الفسفور (PO4):

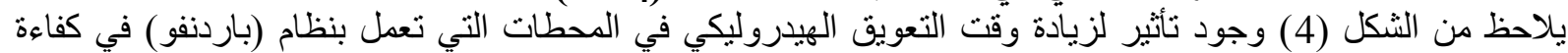

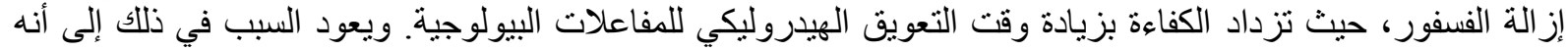

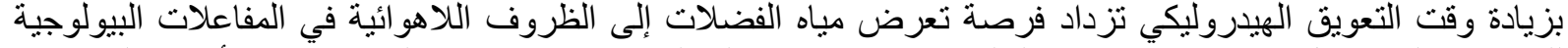

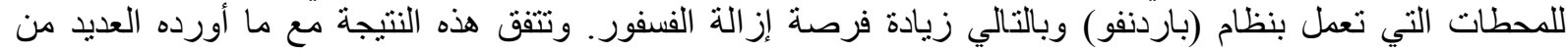

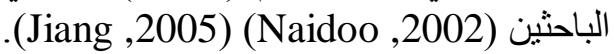


e تأثير وقت المكوث الهيلروليكي في كفاعة أحواض الترسيب:

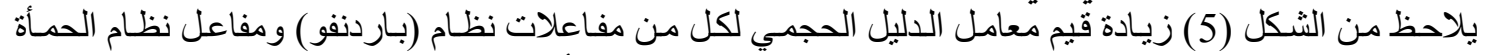

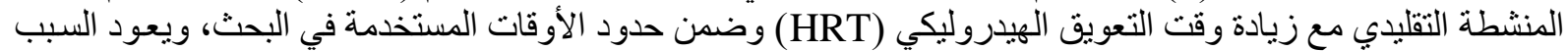

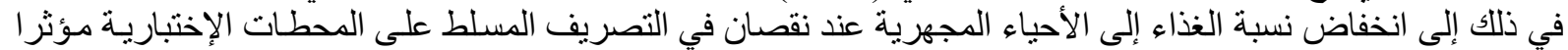

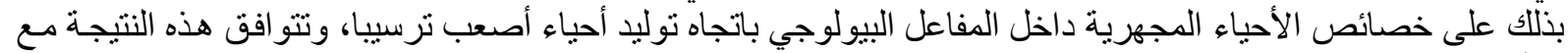
ما أورده (Metcalf and Eddy , 2003).

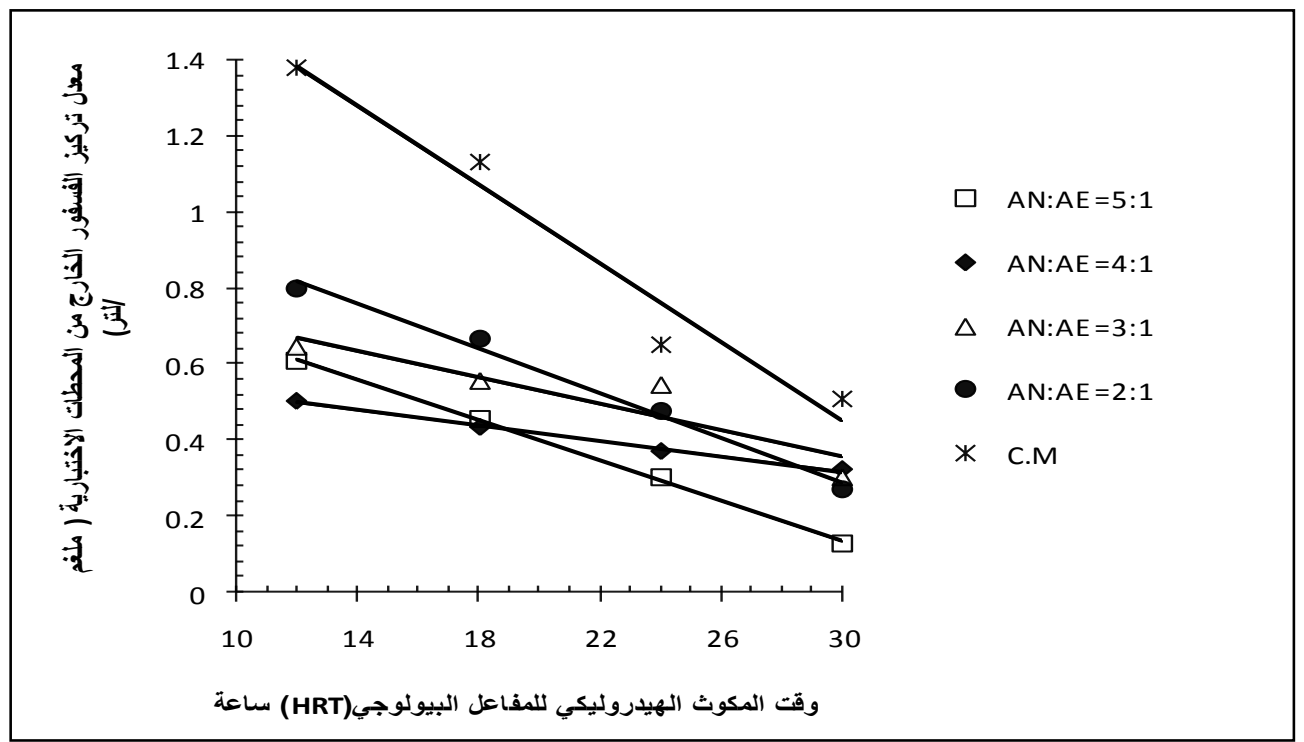

الثكل (4): العلاقة بين وقت التعويق الهيدروليكي (HRT) للمفاعل البيولوجي ومعدل تركيز الفسفور المتبقي الخارج

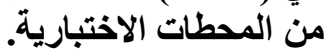

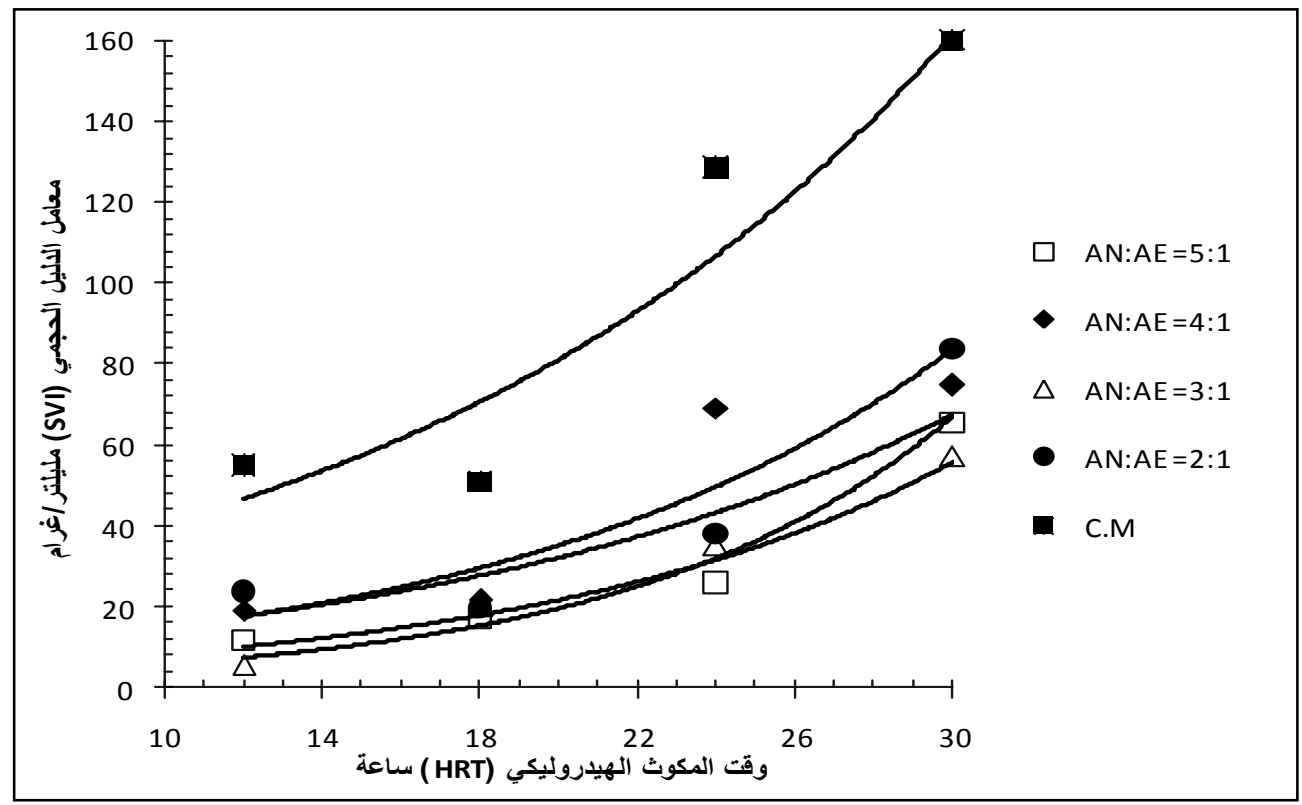

الثكل (5): تغاير معامل الدليل الحجمي (SVI) للمفاعلات الإختبارية مع وقت التعويق الهيدروليكي (HRT). 
2. تأثير تفير النسبة الحجمية للمنطقة اللاهوائية إلى المنطقة الهوائية للمفاعلات البيولوجية التي تعمل بنظام (باردنفو) في سلوك المحطات الاختبارية.

a

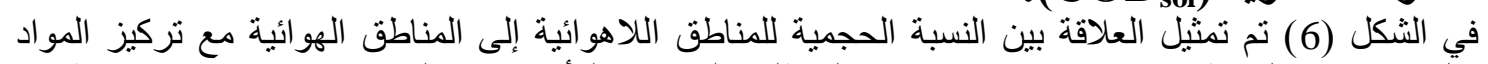

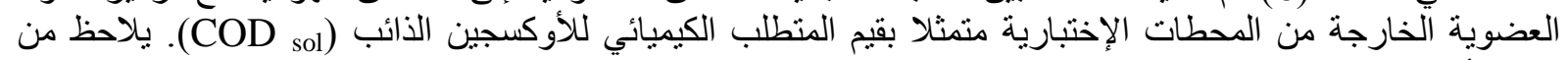

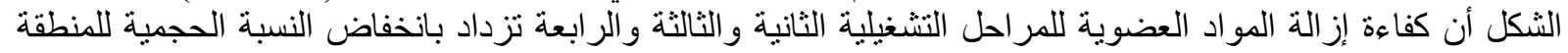

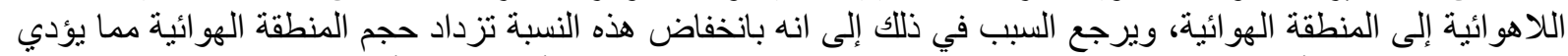

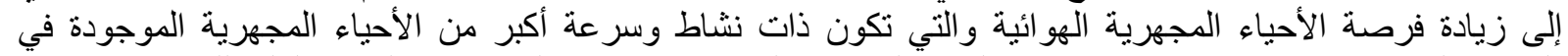

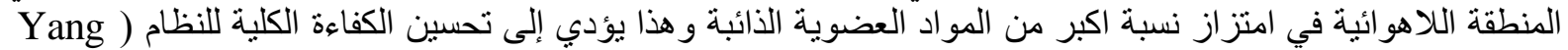

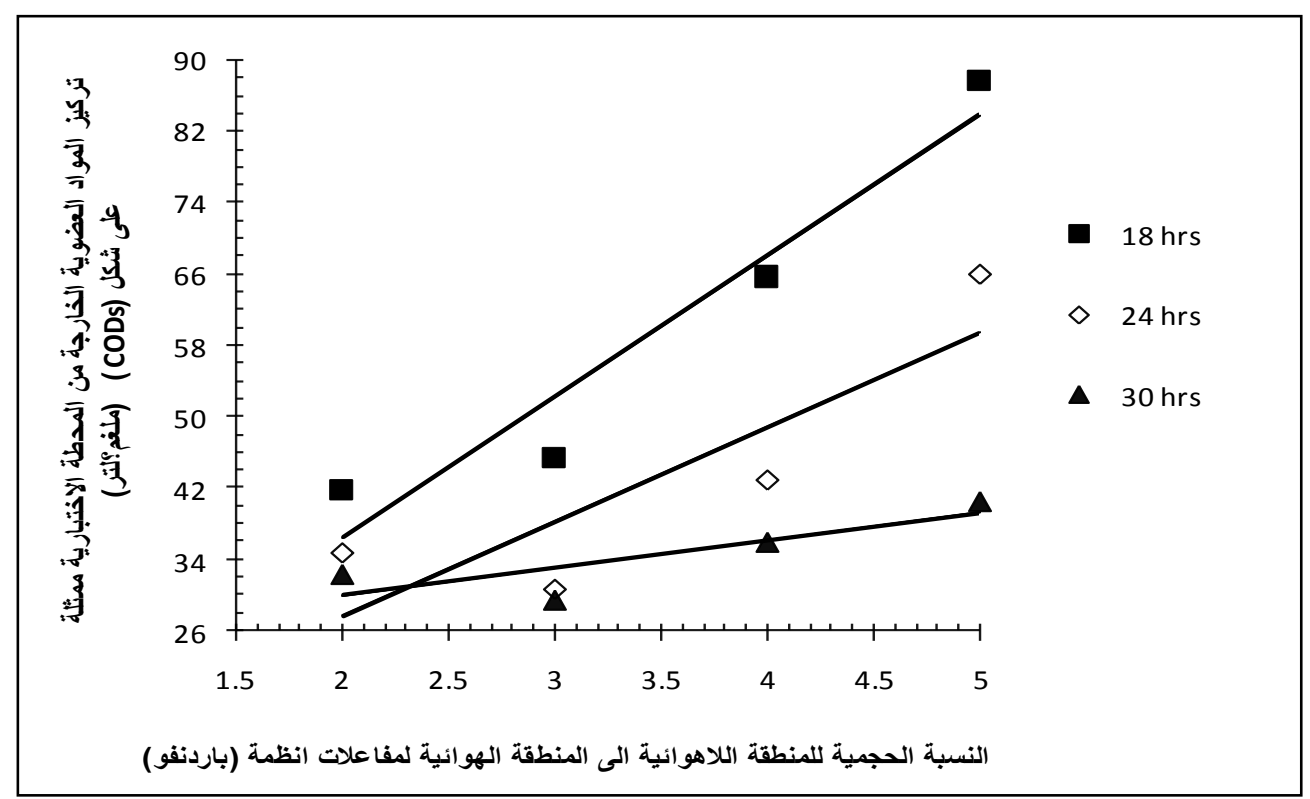

الثكل (6) : العلاقة بين النسبة الحجمية للمنطقة اللاهوائية إلى المنطقة الهوائية في المحطات الإختبارية التي تعمل بنظام (باردنفو) وتركيز المواد العضوية الخارجة من المحطات الإختبارية ملغم /لتر.

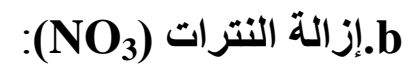
في الثكل (7) تم تمثيل العلاقة بين النسبة المئوية لحجم المنطقة اللاهو ائية إلى المنطقة الهوائية وبين معدل تر اكيز

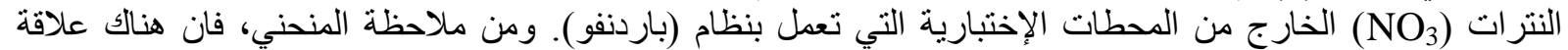

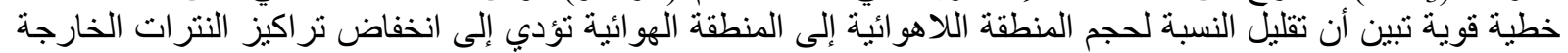

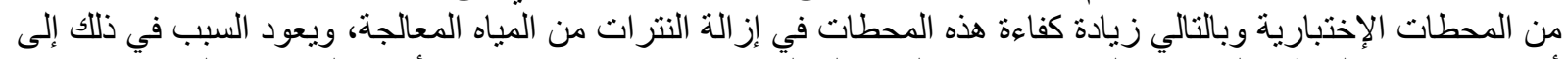

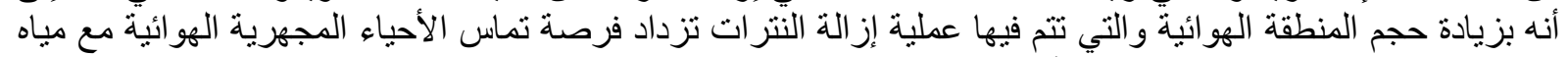

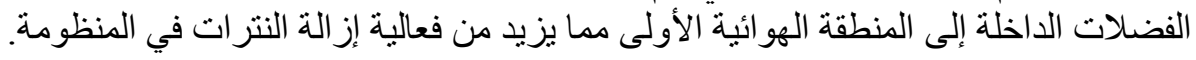




\section{Al-Rafidain Engineering \\ Vol.22 \\ No. 1 \\ February 2014}

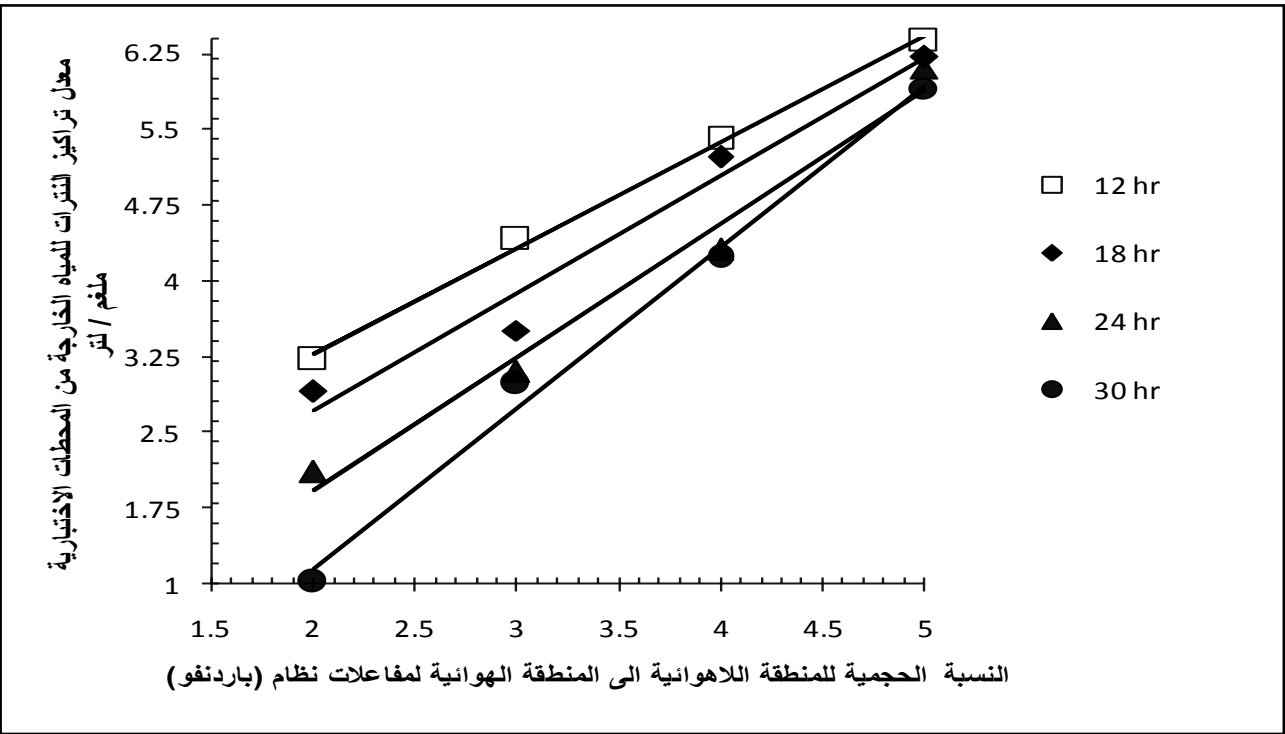

الثكل (7) : العلاقة بين النسبة الحجمية للمنطقة اللاهوائية إلى المنطقة الهوائية في المحطات الإختبارية التي تعمل

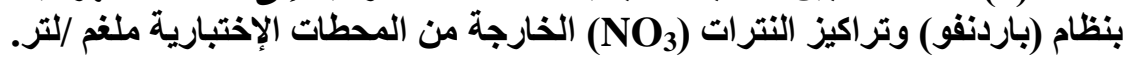

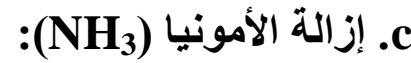

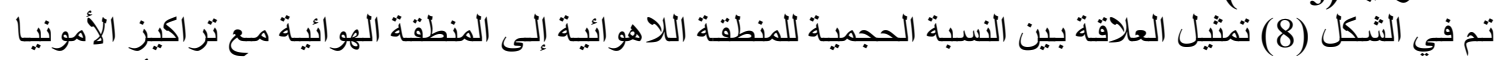

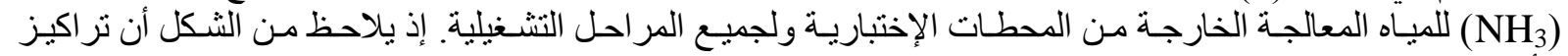

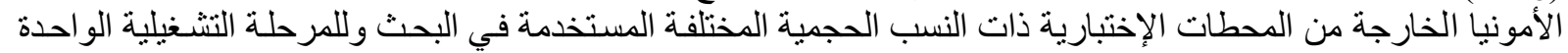

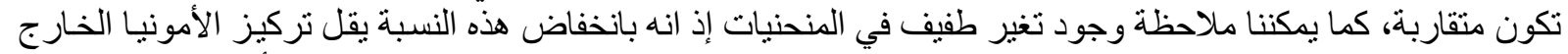

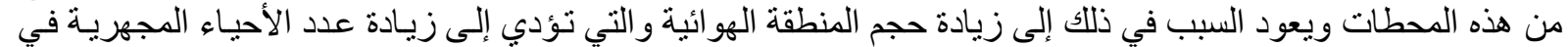

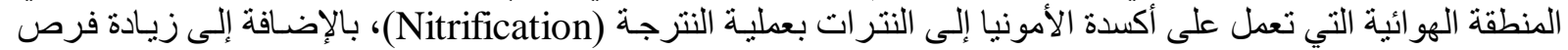
تماس هذه الأحباء مع مياه الفضلات التعل الداخلة إلى المحطة الإختبارية.

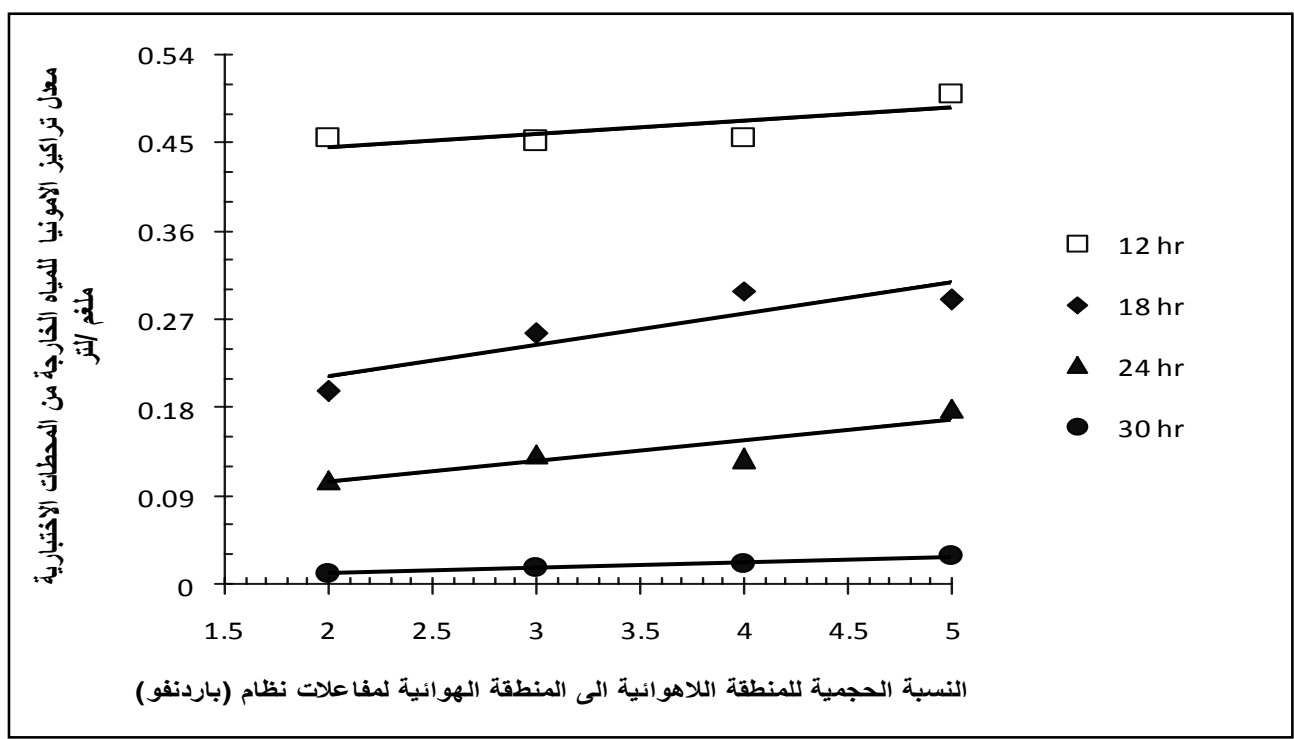

الثكل (8) : العلاقة بين النسبة الحجمية للمنطقة اللاهوائية إلى المنطقة الهوائية في المحطات الإختبارية التي تعمل

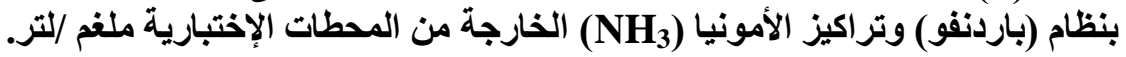


: (إزالة الفسفور (PO)

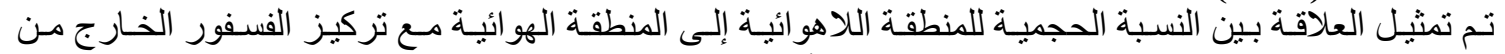

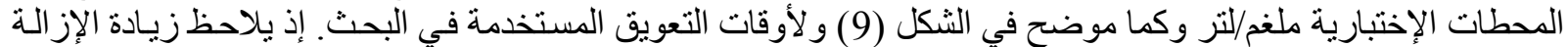

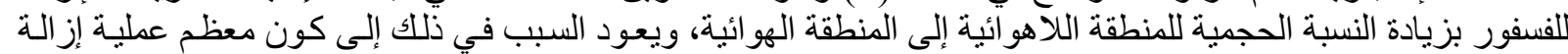

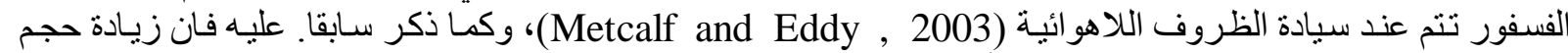

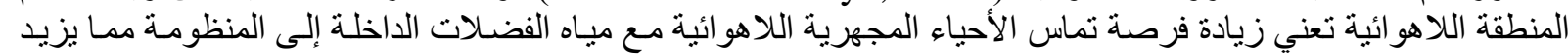

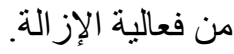

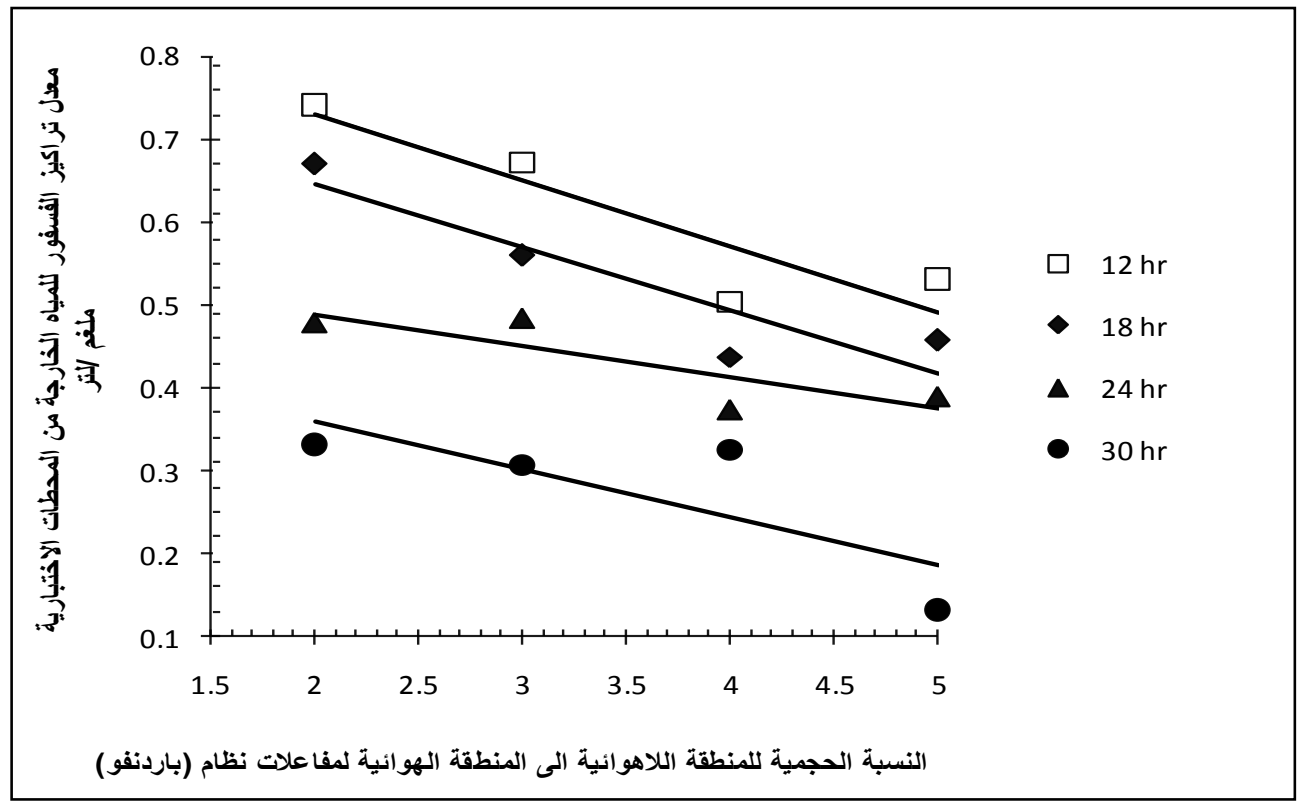

الثكل (9) : العلاقة بين النسبة الحجمية للمنطقة اللاهوائية إلى المنطقة الهوائية في المحطات الإختبارية التي تعمل بنظام (باردنفو) وتراكيز الفسفور (PO4) الخارجة من المحطات الإختبارية ملفم /لتر.

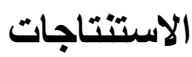

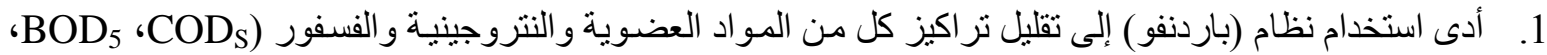

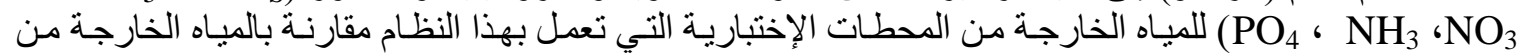

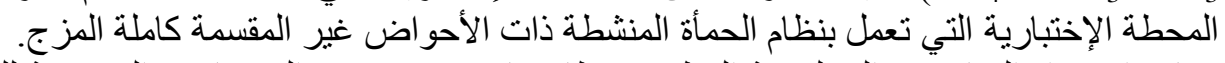

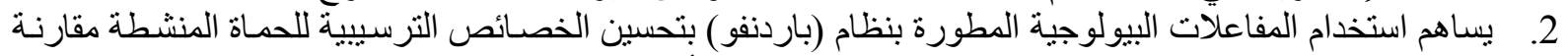

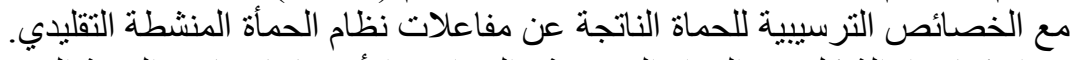

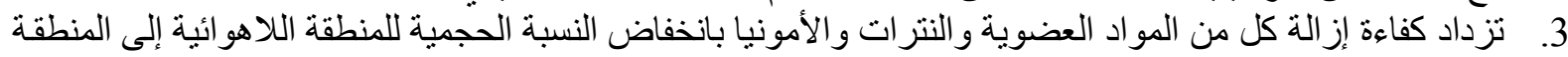

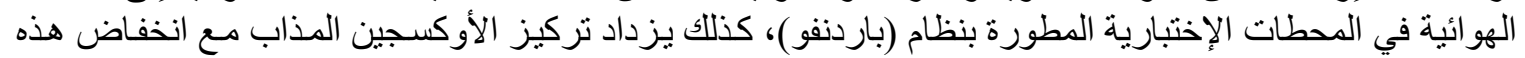

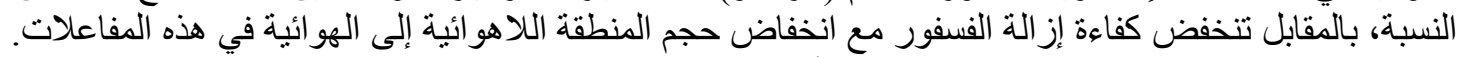

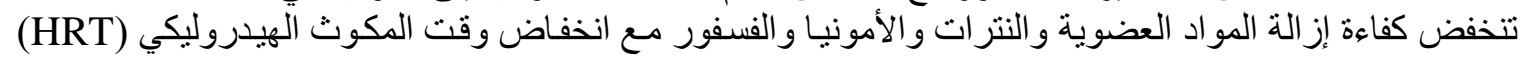
وفي كل من المفاعلات البيولوجية التي تعمل بنظام (باردنفو) ومفاعلات الحماة التيات المنشطة التقليدي.

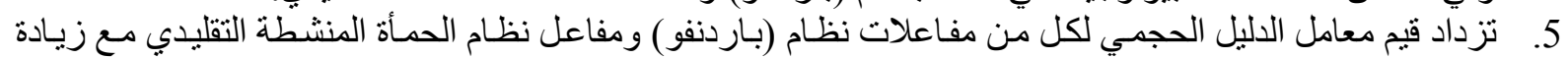
وقت التعويق الهيدروليكي (HRT). 
APHA, (1998), "Standard Methods for the Examination of Water and Wastewater", $20^{\text {th }}$ ed., Washington, D.C.

Azimi A.A., Hooshyari B., Mehrda N. ; and Nabibidhendi GH. (2007), "Enhanced COD and Nutrient Removal Efficiency In a Hybrid Integrated Fixed Film Activated Sludge Process", Iranian Journal of Science \& Technology , Vol. 31, PP. 523-533.

Bracklow U., Drews A., Vocks M. ;and Kraume M. (2007), "Comparison of Nutrients Degradation in Small Scale MBR Fed With Synthetic/Domestic Wastewater", Hazardous Materials, Vol. 144, No. (3), PP. 620-626.

Cech, J. S. and Hartman, P., (1993), " Competition Between Poly-Phosphate \& Polysaccharide Accumulating Bacteria in Enhanced Biological Phosphate Removal Systems", Water Research, Vol. 13, PP. 1213.

Eckenfelder (2000), " Industrial water pollution control", 3rd ed., McGraw-Hill International Edition, Singapore.

Jeyanayagam S. (2005), " True Confessions of the Biological Nutrient Removal Process ", Florida Water Resourses Journal , PP. 37-46.

Kermani M., Bina B., Movahedian H., Amin M. M. and Nikaeen M., (2009) ," Biological Phosphorus and Nitrogen Removal from Wastewater Using Moving Bed Biofilm Process", Iranian Journal of Science \& Technology, Vol. 7, No. 1.

Metcalf and Eddy, Inc. (2003) "Waste water engineering treatment/disposal/reuse", 4th ed., McGraw-Hill, Inc, New York, Ch8, PP. 661-665.

Morgan, S., Boyle, C.A. and Mckenzie, C.J. (2009), "Internal Recycle to Improve Denitrification in Step Feed Anoxic/Aerobic Activated Sludge System", Water Science \& Technology, Vol. 60, No. 7, PP. 1661-1668.

Naidoo, K., Ndlovu, V., Mjadu, L., Treffry-Goatley, K. and Kerdachi, DA. (2002), "The Exceptional Simultaneous Removal of Carbon, Nitrogen and Phosphorus in a Simple Activated Sludge Treatment System at Kings burgh Wastewater Treatment Works ", Iranian Journal of Science \& Technology, PP. 67-72.

Nopens I., Capalozza C. and Vanrolleghem P. A. (2001), "Stability Analysis of a Synthetic Municipal Wastewater", Bimoth Technical Report. Ghent University, Belgium, PP. 22 .

NuriAğdağ O. and Sponza D. (2005), " Anaerobic/Aerobic Treatment of Municipal Landfill Leachate in Sequential Two-Stage Up-Flow Anaerobic Sludge Blanket Reactor (UASB)/Completely Stirred Tank Reactor (CSTR) Systems", Process Biochemistry, Vol. 40, PP. 895-902.

Obaja, D., Mace, S. , Costa, J., Sans, C. and Mata-Alvarez, J. (2002), "Nitrification, Denitrification and Biological Phosphorus Removal in Piggery Wastewater Using a Sequencing Batch Reactor ", Bioresource Technology, Vol. 87, PP. 103-111 .

Ramalho, (1977), " Introduction to Wastewater Treatment Process", Academic press, Inc., Canada. 
Toit, G. du, Parco, V., Wentzed, M. and Ekama, G. (2007), "Biological Nutrient Removal in Membrane Bioreactors : Denitrification \&Phosphorus Removal Kinetics", Water Science \& Technology, Vol. 56, No.6, PP.125-134.

Viessman ,W. Jr. and Hammer, M. J. (1985), "Water Supply and Pollution Control ", Harper and Row Publishers Inc., New York, 4th ed..

Vocks, M., Adam, C., Lesjean, B., Gnirss, R. and Kraume M. (2005), "Enhanced PostDenitrification without Addition of an External Carbon Source in Membrane Bioreactors", Water Research, Vol. 39(14), PP. 3360-3368.

Wanner, J., Ottova, V. and Grau, P. (1987), "Effect of an Anaerobic Zone on Settle ability of Activated Sludge in Biological Phosphate Removal from Wastewaters", Ramadori, R. Ed., Pergamon Press, Oxford, PP. 155.

Yang, P.Y., Zhang, Z. Q. and Jeong, B. G. (1998), "Simultaneous Removal of Carbon and Nitrogen Using an Entrapped Mixed Microbial Cell Process", Water Research, Vol. 31, PP. 2617-2625.

Yoona T., Leeb H.S. and Kim, C. G. (2004), " Comparison of Pilot Scale Performances Between Membrane Bioreactor and Hybrid Conventional Wastewater Treatment Systems", Journal of Membrane Science, Vol. 242, PP. 5-12.

تم اجراء البحث في كلية ألهندة = جامعة ألموصل 